\title{
Cosplay e cosplayers: quando a cultura pop é levada a sério
}

\author{
Barbara Heller
}

NUNES. M. R. F. (org.).

Cena cosplay: comunicação,

consumo, memória nas

culturas juvenis.

Porto Alegre: Sulina,

343p., 2015.

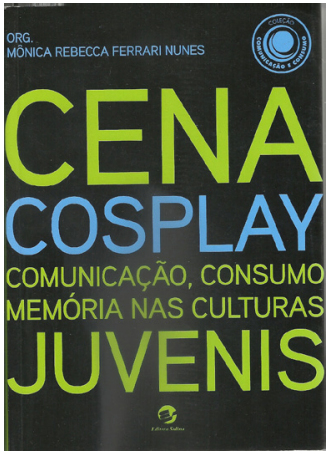

Resumo: Cena Cosplay: comunicação, consumo, memória nas culturas juvenis, organizado por Monica Rebecca Ferrari Nunes, apresenta os resultados de pesquisa com financiamento do CNPq levado a termo por investigadores que a autora coordena no grupo vinculado ao Programa de Pós-Graduação em Comunicação e Práticas de Consumo da ESPM, - SP. Dividido em sete partes, além da apresentação, o livro trabalha em mão dupla: as memórias das narrativas que despertaram o interesse para a prática cosplay e seu "inverso", isto é, as estratégias pelas quais a cena cosplay garante sua memória nas culturas juvenis. luri Lotman, Paul Zumthor, Marshall McLuhan, Monica Rebecca Ferrari Nunes, Roger Silverstone, Mircea Eliade, entre outros, dão sustentação teórica às conclusões dos dez autores dos capítulos que frequentaram, entre 2012 e início de 2014, os eventos dos animês em São Paulo, Belo Horizonte, Rio de Janeiro e Vitória.

Palavras-chave: cosplay; animês; flânerie; consumo; memória.

Abstract: Cosplay and cosplayers: when the pop culture is seriously taken - Cena Cosplay: comunicação, consumo e memória nas culturas juvenis, organized by Monica Rebecca Ferrari Nunes, presents the outcomes of the research coordinated by the author at the Postgraduate Studies in Communication and Consumption Practices, ESPM - SP, sponsored by CNPq. The book has seven parts, besides an introduction and has a two-way approach: the memories of 
the stories that aroused interest in cosplay practice and its "reverse", that is, the strategies by which the cosplay scene ensures its memory in youth cultures. Iuri Lotman, Paul Zumthor, Marshall McLuhan, Monica Rebecca Ferrari Nunes, Roger Silverstone, Mircea Eliade, among others, give the theoretical support of the conclusions of the ten authors of the book, who attended the events of animations (animês) in São Paulo, Belo Horizonte, Rio de Janeiro and Vitoria, from 2012 to the beginning of 2014.Keywords: comics; narrative language; visual communication; semiology.

Keywords: cosplay; animations; flânerie; consumption; memory.

Jovens fantasiados de personagens midiáticos, os cosplayers, a partir da pesquisa liderada por Monica Rebecca Ferreira Nunes, docente do Programa de Pós-Graduação em Comunicação da ESPM-SP, alçaram um novo patamar: o de sujeitos que geram sentidos e múltiplos textos culturais e não mais provocadores de estranhamentos. Suas roupas e performances, analisadas sob a perspectiva dos teóricos da semiótica da cultura da Escola de Tartú-Moscou, são interpretadas por ela e pelos demais autores dos 10 capítulos que compõem o livro como uma semiosfera, isto é, como "o espaço, de caráter abstrato, preenchido pelos signos na cultura e dentro do qual os processos comunicacionais se realizam". (p.24)

Geradores de sentidos, os cosplayers criam textos imprevisíveis e provocam os mais diversos modos de sociabilidade e, também, de memória. Essas são algumas das informações com as quais o leitor encontra logo no primeiro capítulo, redigido pela organizadora.

Mesmo leitores poucos familiarizados com a cultura japonesa aprendem e apreendem a riqueza dos cosplayers jovens e adultos que frequentaram os quinze eventos visitados pelos pesquisadores, entre janeiro de 2012 e maio de 2014, em São Paulo, Belo Horizonte, Rio de Janeiro e Vitória.

Os investigadores praticaram a flânerie como metodologia, isto é, circularam entre os cosplayers para entrevistar, sem duração precisa, aqueles que mais chamaram sua atenção, seja pelas cores de suas vestimentas, pelos personagens que representavam, pela voz que imitavam, pelas performances ensaiadas.

A cena cosplay é esquadrinhada e radiografada em cinco partes homogêneas no livro. Na primeira, "Cosplayers e poetas", Monica Rebecca e Marco Antonio Bin sugerem a permanência do lúdico e a busca por uma representação simbólica para os cosplayers se fazerem ouvir, posição bastante distinta da dos poetas marginais, que buscam uma identidade local e não a do ídolo midiático.

"Percepção, cognição e pertencimento", a segunda parte, traz as contribuições de Ana Maria Guimarães Jorge e Gabriel Theodoro Soares. A passagem que segue: “O cosplayer não se torna o personagem. Ele não ganha seus poderes e ele sabe disso. Mas naquele momento ele finge ser o personagem, pode até mesmo fingir ter poderes, tudo em nome da brincadeira" (p.169) remete aos célebres versos de Fernando Pessoa: 
"o poeta é um fingidor/finge tão completamente/que chega a fingir que é dor/ a dor que deveras sente". Parte-se da constatação de que as análises dos autores aqui citados permitem traçar uma analogia entre o cosplayer e o poeta, uma vez que ambos fazem um jogo entre o que são e o que pretendem ser aos olhos de terceiros.

Michiko Okano e Tatiana Amendola Sanches, na terceira parte, "Moda e estilo urbano", elaboram sofisticada análise para pensar a relação entre cosplays e rolezinhos, aqui definidos como encontros de grande número de jovens da periferia das grandes cidades brasileiras, geralmente em shoppings centers e marcados via redes sociais. Enquanto o segundo escolhe a roupa como fator de distinção social, o primeiro pensa-a como elemento lúdico.

A importância da voz, das onomatopeias dos mangás, do dublador nos animês, do japonismo espalhado pelo ocidente desde a ópera Madama Butterfly, de Giacomo Puccini, a partir de 1853, são largamente analisadas por Luiz Fukushiro e Heloísa de Araújo Duarte Valente. Ainda nesta parte, a quarta, "Matérias sonoras", encontra-se o capítulo de Vera da Cunha Pasqualin, que não só retoma a importância sobre o uso da memória dos leitores em relação aos sons produzidos pelos objetos, ações e elementos da natureza nos mangás, como também valoriza a escuta de rádios web temáticas, especializadas em trilhas sonoras de animês, realizada em campo.

Na parte cinco, encontram-se os artigos de Davi Naraya Basto de Sá e Wagner Alexandre Silva, "Games e colecionismo". Como o próprio título sugere, os pesquisadores tratam de jogos outrora difundidos entre os jovens no Japão e também no Brasil, como "Cavaleiros do Zodíaco", que originaram videogames, jogados coletivamente. Discutem também a prática de colecionar itens e acessórios (buttons, chaveiros, stickers, camisetas, bonés), como estratégia, nem sempre consciente, de o cosplayer se ver mais próximo do universo de fantasia do animê ou do mangá pelo qual desenvolveu maior afinidade.

As partes seis e sete, respectivamente, "Flânerie" e "Sobre os Autores", encerram o livro. Nelas, podemos ver algumas imagens de cosplayers em ação e identificar as biografias dos que contribuíram para a realização da pesquisa, agora registrada em forma de livro.

Finalmente, vale ressaltar que os marcos teóricos que amarram todos os capítulos partem da semiótica da cultura para pensar a memória, o consumo e a cena cosplay. Isso quer dizer que um cosplayer, antes de assumir um determinado personagem, precisou, primeiro, acessar sua memória para, depois, selecioná-lo. Não importa se esse processo foi consciente, mas, isso sim, reconhecer que o resultado final, muito mais que uma "fantasia" ou um "modismo" ou uma "mera brincadeira", é o que luri Lotman e Bóris Uspenskii consideram texto cultural, uma vez que nele comparecem elementos de sua vivência cultural, permeada por permissões, proibições e dialogismo.

Lolita, personagem do romance de Vladimir Nabokov (1950), do filme anglo-estadunidense de Stanley Kubrick (1962) e da cultura pop nipônica (década de 1980) é um dos vários exemplos do livro que permitem compreender com clareza a ideia defendida 
pelos teóricos da semiótica da cultura. Um dos ícones da cultura pop nacional até hoje no Japão, Lolita também ganhou adeptos no Brasil, especialmente a partir da exibição do filme Kamikaze Girls, de 2004, baseada em obra literária de Nobara Takemoto, publicada em 2002.

Enquanto as Lolitas japonesas caracterizam-se, por razões históricas e políticas, de maneira infantilizada, nas brasileiras reconhecem-se características de independência, especialmente em suas posturas, uma vez que algumas são mulheres mais velhas, casadas e atuantes no mercado de trabalho. Se no Japão predomina a questão da fantasia, no Brasil é a procura de uma identidade individual que motiva essas cosplayers. Isso quer dizer que as sensibilidades, experiências de vida e até mesmo condições climáticas modelam, dialogicamente, os estilos, os elementos dos figurinos e as performances das várias Lolitas espalhadas no Oriente e Ocidente.

Os produtos de entretenimento, de maneira geral, são representativos dos estudos semióticos da cultura. Para esses teóricos, a busca pelo outro porque estamos insatisfeitos com aquilo que nos pertence deixa de ser um movimento "exótico" e passa a se constituir em um mecanismo de manutenção da própria cultura. Mesclar, portanto, elementos de mais de uma cultura nada mais é que renová-la para constituir novos textos culturais, como a já citada ópera de Puccini, que agregou elementos orientais à música italiana e no Ocidente, ou a dramatização de uma cena do seriado japonês Romeu X Julieta, que, inspirada em Shakespeare, dá outro contorno ao final trágico do casal apaixonado, típico da cultura nipônica. Nesta série, o casal morre diferentemente da versão inglesa: a jovem mata seu amado com sua espada, como um gesto de sacrifício pelo seu povo e para vingar a morte de seus familiares. Não há veneno, nem suicídio, como pensou o poeta inglês, em 1597.

O consumo de roupas também mostra o jogo de significados múltiplos de um texto cultural. Em janeiro de 2014, Eron Morais de Melo, de 32 anos, protético, foi às ruas do Rio de Janeiro para protestar por diferentes causas, vestido de Batman. Questionado sobre o motivo de seu figurino, afirmou que, ao vesti-lo, sente "o peso da responsabilidade", mas que sua postura é "pacífica", nunca passiva (p.221). Frequentador dos rolezinhos e de cosplays, o Batman brasileiro elege grifes como John John ou Abercrombie \& Fitch, quando seus pares apenas improvisam o que vestir, já que a intenção dos cosplayers é utilizar a roupa como elemento lúdico. Transitando dentro e fora do universo cosplay, Eron materializa a afirmação de identidades e subjetividades dos sujeitos contemporâneos, como forma de superação de distinções sociais e econômicas impostas pelo sistema capitalista.

Tais exemplos, encontrados ao longo dos capítulos, ilustram a pertinência dos referenciais teóricos para pensar a cena cosplay e as suas performances. A escrita fluída de todos os autores e a riqueza das análises tornaram o livro Cena cosplay: comunicação, consumo, memória nas culturas juvenis, de agora em diante, uma referência obrigatória para os pesquisadores interessados na cultura juvenil e pop, especialmente para os que olham a cena cosplay em todos os seus matizes. 
Barbara Heller é docente do PPGCOM da Universidade Paulista (Unip). É pós-doutora em Comunicação pela Universidade Metodista e pela Universidade de São Paulo e doutora em Teoria Literária pela Unicamp.

b.heller@terra.com.br

b.heller.sp@gmail.com 